\title{
Does National Health Insurance Promote Access to Quality Health Care? Evidence from Nigeria
}

\author{
Ade Ibiwoye and Ismail A. Adeleke \\ Department of Actuarial Science and Insurance, University of Lagos, Lagos, Akoka, Yaba, Nigeria. \\ E-mails: adeibiwoye@yahoo.com; adeleke22000@yahoo.ca
}

Since the National Health Insurance Scheme (NHIS) was established in Nigeria, in 1999, not much study has been carried out to investigate whether access to quality health care has improved as a result of the introduction of the scheme. Using primary data from Lagos, this study applies logistic regression to evaluate participation in the NHIS among employees in the formal sector. The study found that although low awareness is a major factor affecting participation in the scheme, the NHIS has the potential to promote access to quality health care particularly among educated couples. In the formal sector participation may be improved if employers comply with the directive making the scheme compulsory for all employees, while in the informal sector it may be improved through an awareness campaign about the benefits of NHIS.

The Geneva Papers (2008) 33, 219-233. doi:10.1057/gpp.2008.6

Keywords: National Health Insurance Scheme; health maintenance organization; access to quality health care; capitation; subscription; formal sector

\section{Introduction}

The health care delivery system in Nigeria has, since the $1980 \mathrm{~s}$, continued to deteriorate. ${ }^{1}$ Paradoxically while health care facilities have been declining, the cost of procuring health care has been growing. With the decline in facilities and the increasing cost of medical care, the problems of geographic and economic barriers to quality health care have worsened. The situation is compounded by the living condition of the population, which was aptly captured by Aigbokan. ${ }^{2}$ He found that, between 1985 and 1996, an increasing number of Nigerians, 38 per cent in 1985, 43 per cent in 1992 and 47 per cent in 1996, were living in absolute poverty. This state of affairs gave room for people to use less expensive, but clearly inferior, medical care, compared to the one provided by medical outlets approved by government. ${ }^{3}$ Among such alternative "providers" could be found spiritual homes, traditional health clinics and self-medication, many of which are of sub-standard quality and inherently unsafe.

In a bid to promote the use of quality health care systems, the government, by Decree No. 35 of 1999, established the National Health Insurance Scheme (NHIS) with the broad objectives of ensuring that every Nigerian has access to good health

\footnotetext{
${ }^{1}$ World Bank (1996).

2 Aigbokan (2000).

${ }^{3}$ Mohammed (2007).
} 
care service at affordable cost. To what extent this objective has been met remains to be ascertained, especially when considered in the light of the World Bank's ${ }^{4}$ report on Participation Poverty Assessment, which had noted that dissatisfaction with government health facilities is a recurring theme that has led to increasing reliance on traditional and informal private health providers throughout the country.

This study uses primary data from Nigeria to assess the contribution of NHIS to health care delivery in a developing economy environment. In particular, it examines the effect of socio-economic factors like age, marital status and level of income on participation in the NHIS, and recommends strategies to improve the use of the NHIS. It seems apposite to start such an investigation with background information on the evolution of the NHIS in Nigeria.

\section{Background}

The plan to establish a national health insurance scheme in Nigeria dates back to 1962 when the role of health insurance in the provision of health care was first advocated by a committee set up by government to look at the ways and means of financing health care. ${ }^{5}$ It was not until 1984, however, that economic depression and persistent decline in the financial allocation to the health sector forced government to take a concrete step by setting up another committee with clear mandate to examine the feasibility of having a health insurance scheme. This latter committee advised that health insurance was desirable and should be adopted. Two other committees followed in 1985, both of which were tasked with formulating an acceptable model for the implementation of the scheme. ${ }^{6}$ In 1995, the National Health Summit endorsed the need to set up the scheme but the enabling law did not come into effect until 1999.

Although the NHIS aims to reach all Nigerians, government was quick to take cue from the experience of other African countries that started the implementation from the informal sector but recorded failures. ${ }^{7}$ It therefore began with pilot schemes in selected states in each of the six geo-political zones and restricted cover to civil servants whose fee could be deducted at source. According to Ogunbekun, ${ }^{8}$ employers in the selected states who had a workforce of 10 or more employees were to ensure mandatory enrolment of their employees in the scheme. It was envisaged that the NHIS would cover six million people (about 5 per cent of the population) in the first phase, progressing subsequently to include those in the informal sector and the rural population.

The scheme is designed to be administered at the centre by the National Health Insurance Council (NHIC) while at the state level the State Health Insurance Board (SHIB) takes charge. The SHIBs are expected to enter into contractual arrangements with primary health care providers, which in turn will interact with sub-providers. So

\footnotetext{
${ }^{4}$ World Bank (1996).

5 Nigeriafirst (2006).

${ }^{6}$ Ibid.

${ }^{7}$ Mohammed (2007).

${ }^{8}$ Ogunbekun (2003).
} 
far a total of 501 primary providers have been registered throughout the country. Each contributor in the NHIS scheme is expected to register, along with his spouse and a maximum of four dependents, with only one provider. A monthly capitation is paid to the provider. This entitles registered employees (under the age of 60) and their families to comprehensive health care benefits subject to a "waiting period" of 5 months. Excluded from the scheme are treatment abroad, dental treatment and private room charge.

The activities of the health care providers are coordinated by health maintenance organizations (HMOs). Specifically, HMOs collect contributions from all eligible employers and employees, pay capitation to health care providers, render returns to NHIC and ensure that contributions are paid into banks in accordance with NHIC guidelines. The HMOs operate on tariffs so as to check excessive bills by health care providers. Presently the distribution of the HMOs appears skewed in favour of Abuja, the new Federal capital, and Lagos, the former capital.

\section{Health care access measures}

A number of previous studies have explored various methods of addressing the problem of accessibility to health care services. Some of them explore accessibility in terms of physical access and, therefore, modelled the problem as one of location-allocation. They include Doherty et al. ${ }^{9}$ and Tanser, ${ }^{10}$ who, in separate works, developed location criteria to maximize access to primary health care facilities in South Africa. Rahman and Smith ${ }^{11}$ used a similar model in conjunction with systems methodology to locate health facilities at the community level in Bangladesh. Other models in a similar vein are Moller-Jensen and Kofie, ${ }^{12}$ Dokmeci $^{13}$ and Bhat and Jain. ${ }^{14}$

Resolving the physical accessibility problem would, however, only take care of just one aspect of the health care provision problems. Other barriers to accessibility exist. For example, internal inefficiency in the health care service delivery chain may also prevent people from using the hospitals. System inefficiency is a problem that cannot easily be dismissed in developing areas. An insight into the magnitude of the problem is provided by the comments credited to Nigeria's immediate past Health Minister, Eyitayo Lambo, who observed that a patient could go to a hospital complaining of one ailment but leave the hospital with a multiplicity of ailments. ${ }^{15}$ Therefore, the efficiency with which available resources are being utilized is a challenge that cannot be overlooked. ${ }^{16}$ Earlier efforts in this direction include those of Barbetta et al., ${ }^{17}$ who used hybrid ordinary least squares and data envelopment analysis (DEA) to compare

\footnotetext{
${ }^{9}$ Doherty et al. (1996).

10 Tanser (2006).

${ }^{11}$ Rahman and Smith (1999).

${ }^{12}$ Moller-Jensen and Kofie (2001).

${ }^{13}$ Dokmeci (1977).

14 Bhat and Jain (2006).

15 Ugoji (2007).

16 Masiye (2007).

${ }^{17}$ Barbetta et al. (2001).
} 
the technical efficiency of Italian hospitals, and those of Dexter and O'Neill, ${ }^{18}$ Zere et al. ${ }^{19} \mathrm{Hu}$ and Huang ${ }^{20}$ and Rebba and Rizzi, ${ }^{21}$ who all applied DEA. In Nigeria the information base is thin, ${ }^{22}$ and it may be difficult to apply such models. It therefore appears that other approaches should be explored.

Perhaps the weightiest factor in the impediments to accessibility to quality health care is cost. Because of the prevalence of poverty, many people who reside in areas that are only a walking distance from a hospital may fail to use such facility because they cannot afford the cost. Although political parties have made free social services - education and health care in particular - campaign issues, the federal government has since realized that public establishments perform inefficiently and has in its reform programmes been trying to pull out by privatizing. Short of giving a subsidy that may be misapplied, therefore, an indirect method to address the cost problem needs to be explored. Health insurance, which is increasingly being recognized as a veritable channel for promoting access to health care, ${ }^{23}$ is one such approach. The advantage of the health insurance approach is that the fee required for treatment would have been prepaid long before an illness sets in, so there is no question of rejection by health care providers on account of inability to pay the fee for the service.

\section{Data and methods}

The main instrument for data collection was by means of a sample survey. Since the government's pilot scheme was targeted at the formal sector, the survey was directed at the urban areas where the majority of the formal sector organizations are located. Lagos State was chosen as the area of study because it hosts the highest number of health maintenance organizations in the country. It also serves as the headquarters for many private and non-governmental organizations with very literate employees who are likely to give better responses than the less literate population in the more rural locations in the hinterland.

The survey that was conducted between April and June 2007 involved the collection of information from individual employees on their perception of the operations of the NHIS scheme from 2000 to 2006. It covered the following major areas: education, income, occupation, family size and gender. The main instrument of the survey was a structured questionnaire.

Although, initially, it was planned to distribute the questionnaire to respondents by post, two difficulties attended this approach. First, there were no reliable mailing lists. The Nigerian Telecommunications (NITEL) that used to publish a list of its subscribers had discontinued the publication, being itself in the process of privatization. Second, the postal system is inefficient. Besides these mailing difficulties, we also

\footnotetext{
18 Dexter and O’Neill (2004).

19 Zere et al. (2006).

${ }^{20} \mathrm{Hu}$ and Huang (2004).

${ }^{21}$ Rebba and Rizzi (2006).

22 See Lewis (2006).

${ }^{23}$ Bhat and Jain (2006).
} 
presumed that the response rate could be improved with a little persuasion during a face-to-face interaction. Therefore, copies of the questionnaire were distributed through trained enumerators who were instructed to make use of, as much as possible, the personnel departments of the various organizations visited.

At the onset, 10 enumerators were sent for training with two HMOs to enable them to experience, first hand, knowledge of the operations of the HMOs. Subsequently, these enumerators were dispatched to 14 purposively selected local government areas (LGAs), out of the 20 LGAs in the state, with instruction to administer the questionnaires to employees in the formal sectors, including banks, insurance companies, state ministries and federal civil service. The 14 LGAs were selected either because they were more easily accessible or because contacts, who could facilitate the administration of the questionnaires, were identified in these areas. The banks where the questionnaire was administered include Bank PHB, First Bank, Oceanic Bank and Skye Bank, cutting across first-generation and second-generation banks. The insurance companies include Leadway and Crusader Insurance Companies. The ministries selected in the civil service naturally included the State Ministry of Health where officials showed a keen interest in the survey. Another was the Ministry of Information. The Nigerian Custom Service represented Federal establishments in Lagos. Sometimes it was possible to collect the completed copies of the questionnaire before leaving the location but most times specific dates for picking them up were set.

\section{Sample characteristics}

Out of the 6,000 questionnaires distributed, a total of 5,126 were returned. Some of the participants in the survey did not meet the scheduled deadline for the return of the completed questionnaire to the relevant personnel department. The arithmetic gives a response rate of 85.4 per cent.

Table 1 provides a cross tabulation of the income of respondents with marital status and participation in NHIS. The income figures from the table show that 83.1 per cent of the respondents earn below naira 1,000,000 (U.S.\$7,692) per annum and 64.8 per cent earn below N500,000 (U.S.\$3,846) per annum.

Another cross tabulation carried out was that of income of respondents with family size and participation in NHIS. This is presented in Table 2. As in the previous case, not all respondents completed this set of questions on the number of children. Two reasons may account for this. Culturally, among many tribes in Nigeria it is taboo to count the number of children one has. This is in spite of acquisition of Western-type education. The other reason would be that some of the respondents have no children yet. The total number of respondents in this case is less than that of the cross tabulation for marital status. This is not unexpected since not all married couples have children. It would appear that the size of the family does not significantly affect the decision to participate in the NHIS scheme as 74.4 per cent of the respondents participate irrespective of the family size.

A third cross tabulation carried out was that of income of respondents with age group and participation in NHIS. This is to check whether there is a particular age bracket when the level of participation is heightened. There are three age groupings. 
The Geneva Papers on Risk and Insurance - Issues and Practice

224

Table 1 Income, marital status and enrolment in NHIS in percentages $(N=4,656)$

\begin{tabular}{|c|c|c|c|c|}
\hline \multirow[b]{2}{*}{ Income per annum } & \multirow[b]{2}{*}{ Marital status } & \multicolumn{3}{|c|}{ Enrolment in NHIS } \\
\hline & & No & Yes & Total \\
\hline \multirow[t]{4}{*}{ Less than 240,000} & Single & 1.95 & 3.26 & 5.21 \\
\hline & Married & 6.10 & 2.29 & 8.38 \\
\hline & Divorced & 0.76 & 0.65 & 1.41 \\
\hline & Widowed & 1.09 & 1.43 & 2.52 \\
\hline \multirow[t]{4}{*}{$240,000-500,000$} & Single & 3.91 & 7.08 & 10.99 \\
\hline & Married & 6.86 & 23.42 & 30.28 \\
\hline & Divorced & 0.78 & 3.26 & 4.03 \\
\hline & Widowed & 0.65 & 1.30 & 1.95 \\
\hline \multirow[t]{4}{*}{$500,000-1,000,000$} & Single & 0.59 & 0.68 & 1.27 \\
\hline & Married & 0.21 & 14.40 & 14.61 \\
\hline & Divorced & 0.23 & 0.84 & 1.07 \\
\hline & Widowed & 0.50 & 0.85 & 1.35 \\
\hline \multirow[t]{4}{*}{$1,000,000-2,400,000$} & Single & 2.51 & 0.87 & 3.38 \\
\hline & Married & 2.29 & 2.29 & 4.57 \\
\hline & Divorced & 0.59 & 0.31 & 0.90 \\
\hline & Widowed & 0.07 & 0.34 & 0.40 \\
\hline \multirow[t]{4}{*}{ Greater than $2,400,000$} & Single & 0.39 & 1.52 & 1.92 \\
\hline & Married & 0.16 & 3.92 & 4.08 \\
\hline & Divorced & 0.11 & 0.76 & 0.87 \\
\hline & Widowed & 0.13 & 0.66 & 0.79 \\
\hline Total & & 29.87 & 70.13 & 100.00 \\
\hline
\end{tabular}

Source: Survey data.

The first are the younger employees between ages 18 and 25, then the middle-age employees between ages 26 and 40 and lastly the older workers who are 40 years old or older. The outcome is presented in Table 3. Although again not all participants completed this set of questions, the response rate was better than in the earlier two cases.

The table reveals that older employees tend to participate more in the NHIS scheme than those in the age group 18-25.

\section{Method}

This section describes the statistical methods used to analyse the data. Among the methods that have been used to investigate the effect of insurance on accessibility to health care is multiple regression. ${ }^{24}$ Our study first uses descriptive statistics

24 Jiang et al. (2003); and Markova (2006). 
Ade Ibiwoye and Ismail A. Adeleke Does National Health Insurance Promote Access to Quality Health Care?

Table 2 Income, family size and subscription to NHIS in percentages $(N=3,262)$

\begin{tabular}{|c|c|c|c|c|}
\hline \multirow[b]{2}{*}{ Income per annum } & \multirow[b]{2}{*}{ No of children } & \multicolumn{3}{|c|}{ Subscription to NHIS } \\
\hline & & No & Yes & Total \\
\hline \multirow[t]{4}{*}{ Less than 240,000} & Less than 2 & 3.35 & 3.50 & 6.85 \\
\hline & $3-4$ & 3.44 & 2.36 & 5.80 \\
\hline & $5-6$ & 1.22 & 0.16 & 1.38 \\
\hline & Greater than 6 & 0.53 & 0.08 & 0.61 \\
\hline \multirow[t]{4}{*}{$240,000-500,000$} & Less than 2 & 3.24 & 9.76 & 13.00 \\
\hline & $3-4$ & 7.32 & 25.06 & 32.37 \\
\hline & $5-6$ & 1.22 & 7.32 & 8.54 \\
\hline & Greater than 6 & 0.42 & 0.55 & 0.97 \\
\hline \multirow[t]{4}{*}{$500,000-1,000,000$} & Less than 2 & 0.21 & 7.32 & 7.53 \\
\hline & $3-4$ & 0.72 & 12.20 & 12.91 \\
\hline & $5-6$ & 0.11 & 3.66 & 3.77 \\
\hline & Greater than 6 & 0.18 & 1.22 & 1.40 \\
\hline \multirow[t]{4}{*}{$1,000,000-2,400,000$} & Less than 2 & 3.14 & 0.08 & 3.22 \\
\hline & $3-4$ & 0.31 & 1.00 & 1.31 \\
\hline & $5-6$ & 0.13 & 0.07 & 0.20 \\
\hline & Greater than 6 & 0.08 & 0.06 & 0.15 \\
\hline Total & & 25.61 & 74.39 & 100.00 \\
\hline
\end{tabular}

Source: Survey data.

to throw light on the data and then applies logistic regression to see how some

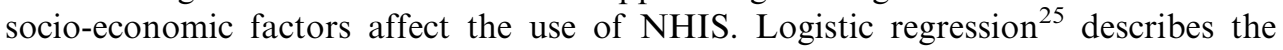
relationship between a dichotomous response variable and a set of explanatory variables.

In our study, we have taken "Enrolment with NHIS" as the categorical response variable. The idea is to assess the effect of certain socio-economic factors like age, income, family size, occupation and gender on utilization of the NHIS. Thus, these factors are treated as the explanatory variables. We constructed two models, one using age, income, gender, occupation and family size as explanatory variables, while the second, in addition to these, also includes education and marital status.

\section{Study results}

We set out below the main results of the study in Table 4. Contrary to what might ordinarily be expected, cost was not the major barrier to access to the NHIS scheme. The percentage recorded for cost was 11 per cent whereas over 36 per cent of the respondents reported not having heard of the NHIS as the reason for not enrolling in

\footnotetext{
${ }^{25}$ see Friendly (1995); Riley (2006) and Garson (2006).
} 
Table 3 Income, age group and subscription to NHIS in percentages $(N=4,684)$

\begin{tabular}{|c|c|c|c|c|}
\hline \multirow[b]{2}{*}{ Income per annum } & \multirow[b]{2}{*}{ Age group } & \multicolumn{2}{|c|}{ Subscription to NHIS } & \multirow[b]{2}{*}{ Total } \\
\hline & & No & Yes & \\
\hline \multirow[t]{3}{*}{ Less than 240,000} & $18-25$ & 2.90 & 0.32 & 3.35 \\
\hline & $26-40$ & 4.93 & 4.55 & 9.85 \\
\hline & $41-60$ & 2.00 & 2.71 & 4.22 \\
\hline \multirow[t]{3}{*}{$240,000-500,000$} & $18-25$ & 2.00 & 0.68 & 2.95 \\
\hline & $26-40$ & 3.95 & 14.39 & 18.18 \\
\hline & $41-60$ & 5.94 & 19.77 & 25.84 \\
\hline \multirow[t]{3}{*}{$500,000-1,000,000$} & $18-25$ & 0.06 & 0.52 & 0.87 \\
\hline & $26-40$ & 1.00 & 6.82 & 7.67 \\
\hline & $41-60$ & 0.05 & 9.32 & 9.63 \\
\hline \multirow[t]{3}{*}{$1,000,000-2,400,000$} & $18-25$ & 0.08 & 0.29 & 0.45 \\
\hline & $26-40$ & 4.92 & 2.74 & 7.98 \\
\hline & $41-60$ & 1.00 & 0.76 & 1.41 \\
\hline \multirow[t]{3}{*}{ Greater than $2,400,000$} & $18-25$ & 0.07 & 0.35 & 0.40 \\
\hline & $26-40$ & 1.00 & 3.44 & 4.10 \\
\hline & $41-60$ & 0.10 & 3.03 & 3.08 \\
\hline Total & & 30.00 & 69.70 & 100.00 \\
\hline
\end{tabular}

Source: Survey data.

the scheme. Another 14 per cent prefer the existing arrangement. This is possibly indicative that either the government is not doing enough publicity or companies are not complying with the directive to enroll their employees in the NHIS scheme.

The decision of the government to direct its initial effort at the formal sector seems to be well informed as the survey revealed a gradual but sure rate of acceptance of the new scheme. The percentage of respondents who use the NHIS option increased from 4.5 per cent in 2000 and 2003 to 13.6 per cent in 2004, 27.6 per cent in 2005 and 31.6 per cent in 2006 .

Among those who were not participating in the NHIS, about half of the total respondents (48.1 per cent) used public hospitals/dispensaries. In Lagos State where successive governments proclaim welfarist policies of free education, free health care services in election campaigns, and where the majority of the employees are civil servants, this tendency is quite understandable. However another high percentage, 44.3 per cent, reported that they made use of private hospitals. Given the relative high cost of service in the private hospitals, the regulator may have to examine the practice in the private sector to know what makes these hospitals attractive to patients and in order to adopt such practices in the NHIS scheme.

Among the remaining respondents, 2.8 per cent use drug stores while 4.8 per cent alluded to other factors as reasons for not enrolling in NHIS. In this last group, there was a preponderance of answers like "God is my healer", "God is my doctor". This is 
Table 4 Characteristics of Lagos NHIS subscribers $(N=5,126)$

\begin{tabular}{|c|c|}
\hline Variables & Percentage \\
\hline \multicolumn{2}{|c|}{ If an enrollee, year of enrolment with HMO in NHIS scheme } \\
\hline 2000 & 4.5 \\
\hline 2003 & 4.5 \\
\hline 2004 & 13.6 \\
\hline 2005 & 27.6 \\
\hline 2006 & 36.4 \\
\hline \multicolumn{2}{|c|}{ If no, reason for not enrolling with an NHIS between 2000 and 2007} \\
\hline Too expensive/can't afford & 11.0 \\
\hline Not heard about HMO & 36.3 \\
\hline Prefer existing arrangement & 14.3 \\
\hline No HMO is available where I work & 5.4 \\
\hline Other reasons & 33.0 \\
\hline \multicolumn{2}{|c|}{ If you do not use the NHIS which of the following do you use? } \\
\hline Public hospital/dispensary & 48.1 \\
\hline Private hospital & 44.3 \\
\hline Drug store & 2.8 \\
\hline Other & 4.8 \\
\hline \multicolumn{2}{|c|}{ Do you also use health care providers outside your NHIS/HMO network? } \\
\hline Yes & 43.5 \\
\hline No & 56.5 \\
\hline \multicolumn{2}{|c|}{ Have you encountered any problem when you visited your health care provider? } \\
\hline Yes & 40.5 \\
\hline No & 59.5 \\
\hline \multicolumn{2}{|c|}{ If you encountered any problem with your provider, what type? } \\
\hline Long queue & 37.8 \\
\hline Expensive drugs & 14.3 \\
\hline Poor reception/Unfriendly health care workers & 19.0 \\
\hline Unclean environment & 4.8 \\
\hline Lack of doctors & 3.5 \\
\hline Inefficient treatment & 18.1 \\
\hline Others & 2.5 \\
\hline \multicolumn{2}{|l|}{ How did you react to the problem? } \\
\hline Continue using the HMO & 26.9 \\
\hline Use other HMO & 42.3 \\
\hline Self-medication & 11.5 \\
\hline Others & 19.2 \\
\hline \multicolumn{2}{|c|}{ How would you compare the deduction from your salaries after enrollment with an HMO with that before } \\
\hline Much more & 14.8 \\
\hline Almost the same & 18.5 \\
\hline Less & 29.6 \\
\hline Don't know & 37.0 \\
\hline
\end{tabular}


Table 4 (continued)

\begin{tabular}{lc}
\hline Variables & Percentage \\
\hline In addition to premium paid to NHIS how much extra do you expend on health care monthly? \\
$\mathrm{N} 1,000$ & 50.0 \\
$\mathrm{~N} 2,000$ & 16.7 \\
$\mathrm{~N} 15,000$ & 13.2 \\
$\mathrm{~N} 20,000$ & 20.2 \\
\hline
\end{tabular}

Source: Survey data.

in tandem with the findings of the World Bank, ${ }^{26}$ which observed that approved government health care providers tend to overlook "spiritual" aspects of illness in their provision. The outcome is not surprising given the widespread phenomenon of faith clinics in Lagos.

More than half of the respondents (56.5 per cent) did not use health care providers outside those in the network of the HMO they registered for. This is probably a carry-over from the previous practice in which organizations retain a doctor for the health care of their employees. It is not inconceivable that the personnel office would not settle the bill of those who use health care providers outside those in the network of the HMO selected by an organization.

About 60 per cent of the respondents reported that they encountered problems with their health care providers. A large proportion (37.8 per cent) put the blame on long queues. Some, 19 per cent, were not pleased with the poor reception received from unfriendly health workers, while 14.3 per cent thought that the drugs that were dispensed were expensive. The position of these respondents is better appreciated when considered against the backdrop that many people use drugstores and think they have a good idea of the cost of drugs. A high percentage (18.1 per cent) put the problem on inefficient treatment while those who thought the problem is with unclean environment were 4.8 per cent.

Respondents' reactions to the problems encountered with their $\mathrm{HMO} /$ health care provider vary. About a third of the respondents (27 per cent) reported that in spite of observed inefficiency they continued to use particular HMOs. This may be either because the HMO is not prepared to change the offending provider or because other providers are too distant from the patient. However, 42.3 per cent of the respondents switched to other providers within the network while 11.5 per cent resorted to selfmedication. Other unspecified reasons sum up to 19 per cent. One half of the total number of respondents ( 50 per cent) claimed that they spent about N1,000 (about U.S.\$7.6) monthly out-of-pocket on health care. Those who spent N2,000 (about U.S.\$15) were 16.7 per cent. The respondents who reported spending N15,000 (about U.S.\$115) or more out-of-pocket were 33.4 per cent.

That a majority of the respondents (66.7 per cent) state that they spend less than N2,000 (about U.S.\$15) per month out-of-pocket would, considering the pay structure

\footnotetext{
${ }^{26}$ World Bank (1996)
} 
in Nigeria, look plausible. The national minimum wage is only N5,500 (about U.S.\$42) per month and the figures for the states are even lower. It also looks reasonable because for ailments that require only a few naira, even supposedly better informed employees would prefer to go to neighbourhood drugstores than go and queue in a government hospital. Other problems reported include lack of competent doctors. This tends to support the fear that in order to maximize profit some of the providers might employ less expensive and therefore less experienced doctors in order to maximize their profit.

The long queues observable in the operation of the scheme have wide implications for time management. When workers spend a disproportionate amount of time trying to get treated at the HMOs a number of man-hours are lost. In the case of poor reception or unfriendly attitude of health care workers, there is a need to train the health workers, especially in the light of the business approach of the NHIS scheme, that the customer is king and that without them there is no employment. In the health sector, there are more than enough reasons for this. The high percentage of those who switch from one health care provider to another has personnel policy implications and raises some questions. How often can an employee change health care providers within the same HMO network? What are the criteria to look for in an HMO in order to prevent frequent switches? What are the regulatory implications?

Next, we examine how socio-economic factors affect the use of NHIS and, hence, how they help to predict how these factors either facilitate or hinder usage of NHIS by fitting a logistic model to the data.

Table 5 reports the result of the two logistic models at the 95 per cent significance level. It is particularly instructive to note that except for income less than N100,000 (about U.S.\$770) all the factors are highly significant at the 99 per cent level. This is indicative of a positive relationship between the independent variables and the explanatory variable. This implies that gender, age, income group and the occupation of an employee all have an influence on the likelihood of the participation of an employee in the NHIS scheme.

These characteristics are true for both Model 1 and Model 2. More specifically, the odds ratio for income below N500,000, age and occupation are all greater than 1 . This suggests that those in the group 26-40 are 1.2 times more likely to subscribe to NHIS than those in the other age brackets. At the 99 per cent confidence level (Model 2), those whose occupation is in the civil service are 3.189 times more likely to subscribe to NHIS than those in other occupations. This is clear from the fact that they are obligated to do so.

Employees who are married are 4.528 times more likely to subscribe to NHIS than those who are not married. Employees with a degree are 1.518 more likely to subscribe to NHIS than those who are not as well educated. Model 1 shows that those earning between N240,000 and 500,000 (between U.S.\$1846 and U.S.\$3846) are 2.489 times more likely to subscribe to NHIS than those in the other income groups. In model 2, the ratio is even higher as it shows that those earning between $\mathrm{N} 240,000$ and N500,000 are 5.784 times more likely to subscribe to NHIS than those in the other income groups

A comparison of the log likelihood value for the two models shows that Model 2 has a lower magnitude for the $\log$ likelihood. It is therefore a better fit. Also from Model 2 we see that married, educated employees who are in the lower income group (less than 
Table 5 Logistic regression models predicting participation in NHIS among employees in the formal sector in Lagos

\begin{tabular}{|c|c|c|c|c|c|}
\hline & & \multicolumn{2}{|c|}{ Model 1: } & \multicolumn{2}{|c|}{ Model 2: } \\
\hline & & Odds ratios & $\begin{array}{c}95 \% \text { confidence } \\
\text { interval }\end{array}$ & Odds ratios & $\begin{array}{c}95 \% \text { confidence } \\
\text { interval }\end{array}$ \\
\hline \multicolumn{6}{|l|}{ Variables } \\
\hline \multicolumn{6}{|l|}{ Sex } \\
\hline & Male & 0.372 & $(0.330,0.420)^{* *}$ & 0.565 & $(0.493,0.646)^{* *}$ \\
\hline \multicolumn{6}{|l|}{ Age } \\
\hline & $26-40$ & 1.207 & $(1.067,1.365)^{* *}$ & 0.639 & $(0.556,0.735)^{* *}$ \\
\hline \multicolumn{6}{|l|}{ Income } \\
\hline & Less than 100,000 & 1.279 & $(0.958,1.709)^{*}$ & 2.154 & $(1.525,3.042)^{* *}$ \\
\hline & $240,000-500,000$ & 2.489 & $(1.943,3.189)^{* *}$ & 5.784 & $(4.288,7.802)^{* *}$ \\
\hline & $500,000-1,000,000$ & 0.590 & $(0.449,0.776)^{* *}$ & 0.549 & $(0.391,0.769)^{* *}$ \\
\hline \multicolumn{6}{|c|}{ Number of children } \\
\hline & Less than 2 & 0.381 & $(0.322,0.450)^{* *}$ & 0.345 & $(0.283,0.421)^{* *}$ \\
\hline & $3-4$ & 0.233 & $(0.199,0.273)^{* *}$ & 0.170 & $(0.144,0.202)^{* *}$ \\
\hline \multicolumn{2}{|c|}{ Occupation (Civil service) } & 1.957 & $(1.761,2.175)^{* *}$ & 3.189 & $(2.857,3.560)^{* *}$ \\
\hline \multicolumn{2}{|c|}{ Education (Degree) } & & & 1.518 & $(1.433,1.608)^{* *}$ \\
\hline \multicolumn{2}{|c|}{ Marital status (Married) } & & & 4.528 & $(3.576,5.733)^{* *}$ \\
\hline \multicolumn{2}{|c|}{$N$} & 5126 & & 5126 & \\
\hline \multicolumn{2}{|l|}{$R^{2}$} & 0.212 & & 0.295 & \\
\hline \multicolumn{2}{|l|}{-log likelihood } & $4,207.84$ & & $3,662.86$ & \\
\hline \multicolumn{2}{|l|}{$\chi^{2}$} & 1028.287 & & 684.795 & \\
\hline
\end{tabular}

N500,000) have a high tendency to subscribe to NHIS. This contrasts with the attitude of married and educated employees in the higher income brackets (above N500,000), who presumably often have wider options, including the use of fee-for-service private hospitals and foreign treatment. Although the $R^{2}$ suggests that only about 30 per cent (Model 2) of the subscription to NHIS is explained by the respective logistic models, this points to the direction for future research as it is not unlikely that "spiritual" aspects - religious beliefs and myths - tend to influence subscription to NHIS to a greater extent than participants in the survey have volunteered.

\section{Conclusion and way forward}

The study shows that on the scale at which the NHIS scheme is being operated, it has the potential to promote access to quality health care and that socio-economic factors, such as marital status, level of education, income and size of family, affect level of participation in the NHIS scheme. Those in the income group N240,000-500,000 are many times more likely to participate in NHIS. This is the middle-income group to 
which most civil servants who have been compelled by their employer to register in the scheme belong. The significance of this is that a high level of participation is witnessed in this group because of the role of the employer. Therefore, if more private sector employees are to participate in the scheme, the NHIC should enforce compliance by the employers of the directive making the scheme mandatory as the public service employers have done.

Presently there are at least three tiers of health care providers. There are the NHISbased health care providers whose fees are capitation based, fee-for-service private hospitals and government hospitals that offer free medical service. Employees who choose fee-based private hospitals despite paying capitation are only exercising their right to choose. However, a system whereby the hospital bills of formal sector employees are deducted at source by way of capitation fee and informal sector employees attend government hospitals where they are offered free service cannot be equitable. It would be difficult in such a setting to ask the informal sector employees to switch to the NHIS scheme. The way to reverse the trend may be to also make government hospitals capitation-based. Government may then have a special scheme for those who are proven to be poor in order to help them settle their capitation fees.

Ultimately, to achieve the objective of making quality health care accessible to all the population through the NHIS, the scheme must be embraced by the informal sector that would now need to choose between capitation-based providers and feebased private providers. Since a high percentage of the respondents stated that lack of awareness was responsible for not participating in the NHIS, there is a need to raise the level of awareness of the scheme. This will require public education since with the informal sector there is no employer to make the scheme mandatory. To facilitate this process, the result of this study can serve as a guide for the government agency to structure its awareness education about the benefits of the NHIS scheme. An initial campaign can be targeted at educated couples (specifically degree holders) among the population since the study has shown that this group has a higher propensity to subscribe to NHIS than the less educated and single employees. These, having been convinced of the advantages of NHIS over the other options, will then serve as role models for the members in the other groups.

\section{References}

Aigbokan, B.E. (2000) 'Poverty, growth and inequality in Nigeria: A case study', taken from http:// unpan1.un.org/intradoc/groups/public/documents/IDEP/UNPA003895.pdf.

Barbetta, G.P., Turati, G. and Zago, A.M. (2001) 'On the impact of ownership structure and hospital efficiency in Italy', taken from www.uniovi.es/7ewepa/pdf/barbetta.PDF, accessed 8 August 2007.

Bhat, R. and Jain, N. (2006) Factoring affecting the demand for insurance in a micro health insurance scheme, IIMA working paper 2006-07-02, http://www.iimahd. ernet.in/publications/data/2006-07-02rbhat.pdf.

Dexter, F. and O'Neill, L. (2004) 'Data envelopment analysis to determine by how much hospitals can increase elective inpatient surgical workload for each specialty', taken from http:/www.anesthesiaanalgesia.org/cgi/content/full/99/5/1492-1500.

Doherty, J., Rispel, L. and Webb, N. (1996) 'Developing a plan for primary health care facilities in Soweto, South Africa. Part II: Applying locational criteria', Health Policy and Planning 11: 394-405.

Dokmeci, V.F. (1977) 'A quantitative model to plan regional health facility systems', Management Science 24: 411-419. 
Friendly, M. (1995) 'Categorical data with graphics', from http://math.yorku.ca/SCS/Courses/grcat/ grc6.html, accessed 4 August 2007.

Garson, G.D. (2006) 'Logistic regression', from http://www2.chass.ncsu.edu/garson/PA765/logistic.htm, accessed 4 August 2007.

$\mathrm{Hu}$, J.L. and Huang, Y.F. (2004) 'Technical efficiency in large hospitals: A managerial perspective', International Journal of Management 21: 506-513.

Jiang, Y., Asfaw, A. and von Braun, J. (2003) 'Performance of existing rural cooperative medical scheme and willingness to pay for the improved scheme', from http:/www.tropentag.de/2003/abstracts/full/ 104.pdf.

Lewis, M. (2006) Governance and corruption in public health care systems, Center for Global Development working paper no. 78, Washington, DC.

Markova, N. (2006) How does the introduction of health insurance change the equity of health care provision in Bulgaria?, IMF working paper WP/06/285, Washington, DC.

Masiye, F. (2007) 'Investigating health system performance: An application of data envelopment analysis to Zambian hospitals', BMC Health Services Research 7: 58.

Mohammed, D. (2007) 'National Health Insurance Scheme, OBJ's best legacy', from http://www.abujain quireronline.com/fetcher.php?fid=1532, accessed 27 May 2007.

Moller-Jensen, L. and Kofie, R. (2001) 'Exploiting available data sources: Location/ allocation modeling for health service planning in rural Ghana', Annual Review of Public Health 24: 25-42.

Nigeriafirst (2006) 'National Health Insurance Scheme takes off', from http://www.nigeriafirst.org/ printer_255.shtml, accessed 23 October 2007.

Ogunbekun, I. (2003) 'Health insurance: A viable approach to financing health care in Nigeria?', from http:// www.jsi.com/intl/init/inspap.htm, accessed 26 October 2003.

Rahman, S.-U. and Smith, D.K. (1999) 'Deployment of rural health facilities in a developing country', Journal of Operational Research Society 50: 892-902.

Rebba, V. and Rizzi, D. (2006) Measuring hospital efficiency through data envelopment analysis when policymakers' preferences matter - An application to a sample of Italian NHS hospitals, working papers, Department of Economics, Ca' Foscari University of Venice No. 13, Venice.

Riley, G.F. (2006) 'Health insurance and access to care among social security disability insurance beneficiaries during the medicare waiting period', Inquiry 43: 222-230.

Tanser, F. (2006) 'Methodology for optimizing location of new primary health care facilities in rural communities: A case study in KwaZulu-Natal, South Africa', Journal of Epidemiology and Community Health 60: 846-850.

Ugoji, E. (2007) 'Nigiria: Health sector reform not for grassroots?', allafrica.com/stories/200706220705, accessed 30 August 2007.

World Bank (1996) Nigeria - poverty in the midst of plenty: The challenge of growth with inclusion, report 14733-UNI, Population and Human Resources Division, Washington, DC.

Zere, E., Mbeeli, T., Shangula, K., Mandlhate, C., Mutirua, K., Tjivambi, B. and Kapenambili, W. (2006) 'Technical efficiency of district hospitals: Evidence from Namibia using data envelopment analysis', from http://www.pubmedcentral.nih.gov/articlerender.fcgi?artid=1524815, accessed 16 February 2007.

\section{About the Authors}

Ade Ibiwoye teaches Actuarial Mathematics, Operation Research and Financial Mathematics in the Department of Actuarial Science \& Insurance, Faculty of Business Administration, University of Lagos, Nigeria. He has about 10 years of cognate experience in the Insurance Industry as a Consultant in Pensions and Employee Benefits.His research interest covers Life and Health Insurance, Pension, Actuarial Modelling, Survival Analysis and Optimization Modelling. He is a Fellow of the Institute for Operations Research of Nigeria and member of several learned professional bodies. 
Ismail A. Adeleke is a lecturer in the Department of Actuarial Science \& Insurance, Faculty of Business Administration, University of Lagos. He has over 5 years teaching and research experience in the university where he teaches Statistics and Mathematics. His area of specialization includes Statistical Computing \& Data Analysis, Sampling Technique, and Multivariate Techniques. He is a member of several learned professional bodies. 